\title{
INJECTABLE MICROCARRIERS AS HUMAN MESENCHYMAL STEM CELL SUPPORT AND THEIR APPLICATION FOR CARTILAGE AND DEGENERATED INTERVERTEBRAL DISC REPAIR
}

\author{
A. Bertolo ${ }^{1}$, S. Häfner ${ }^{1}$, A.R. Taddei ${ }^{2}$, M. Baur ${ }^{3,4}$, T. Pötzel ${ }^{4}$, F. Steffen ${ }^{5}$ and J. Stoyanov ${ }^{1,6^{*}}$ \\ ${ }^{1}$ Swiss Paraplegic Research, Nottwil, Switzerland \\ ${ }^{2}$ Center for High Instruments, Tuscia University, Viterbo, Italy \\ ${ }^{3}$ Cantonal Hospital of Lucerne, Lucerne, Switzerland \\ ${ }^{4}$ Swiss Paraplegic Centre, Nottwil, Switzerland \\ ${ }^{5}$ Small Animal Hospital, University of Zurich, Switzerland \\ ${ }^{6}$ Institute for Surgical Technology and Biomechanics, University of Bern, Switzerland
}

\begin{abstract}
Degeneration of the intervertebral disc (IVD) is a progressive and chronic process, and the high incidence of discogenic disorders calls for new therapeutic approaches, such as cell-based therapies using three dimensional cultures and mesenchymal stem cells (MSC), which can differentiate to chondrogenic- and IVD-lineages. Here, we investigated the growth and differentiation of human MSC culture on biodegradable collagen scaffolds in order to obtain an injectable suspension. Commercially available wound dressings were downsized to dimensions between 100 and $1500 \mu \mathrm{m}$ and seeded with freshly isolated or early passages MSC. Proliferation rate and chondrogenic differentiation potential was tested at oxygenation levels of $2 \%, 5 \%, 10 \%$ and $21 \%$ in static and dynamic cultures. Evaluation methods included cell viability test, disc marker genes expression (aggrecan, collagen type I and type II), histological detection of proteoglycans and immunohistochemical analysis. On microcarriers, freshly isolated MSC had lower proliferation rate and chondrogenic differentiation potential compared with early passages MSC. Proliferation of MSC was significantly increased 1.7 -fold at $5 \%$ oxygen level and in combination with dynamic culture was further increased to 2.3-fold, with respect to normoxia. Chondrogenesis was positively affected by $2 \%$ and $5 \%$ hypoxia, as shown by increased transcription levels and protein expression of collagen type II and proteoglycan accumulation in static cultures, while it was inhibited in dynamic cultures. Collagen type I and aggrecan expression were not affected by hypoxia. In conclusion, collagen based microcarriers are a suitable support for in vitro MSC growth and chondrogenesis especially when cultured at $5 \%$ oxygen level.
\end{abstract}

Keywords: human mesenchymal stem cells, chondrogenesis, collagen microcarriers, dynamic cultures and hypoxia.

*Address for correspondence:

Jivko Stoyanov

Biomedical Laboratories

Swiss Paraplegic Research G.A.Zäch

Strasse 4

CH-6207 Nottwil, Switzerland

Telephone: +41 41-939-6635

Fax: +41 41-939-6640

E-mail: jivko.stoyanov@paranet.ch

\section{Introduction}

Musculoskeletal disorders affecting the spine and its surrounding tissues are responsible for most types of back pain. Muscles, ligaments, bones, joints and nerves can be involved, and triggering factors can be cumulative trauma, excessive biomechanical stress, inflammation and bad posture combined with genetic predisposition (Osborne et al., 2012). Principally, the lumbar spine and the corresponding intervertebral discs (IVD) are affected by such factors: in fact, disc degeneration disease (DDD) is diagnosed in more than $40 \%$ of patients who had low back pain (Freemont et al., 2002) present as narrowed, bulged or prolapsed discs, but also particular postural deformities of the spinal column (Battie et al., 2004). Both conservative and surgical state-of-the-art treatments for IVD-related problems are symptomatic, and although they can be effective against pain in short and middle terms, none of these treatments are curative and efficacy in pain relief in some cases of DDD are not satisfying. In the last decades, several approaches aiming on regeneration of the IVD have been proposed - including in situ injections of growth factors (Masuda et al., 2004), gene therapies (Woods et al., 2011) and cell-based therapies (Meisel et al., 2007). Because of the lack of sustainable sources of autologous IVD cells, the preferred cell type for cell-based therapies of DDD are mesenchymal stem cells (MSC) - multipotent precursor cells which maintain the replacement pool for tissue regeneration (Caplan, 1991) of the musculoskeletal system, not only muscles, tendons and ligaments, but also adipose, bone and cartilage tissues (Pittenger et al., 1999). Key elements to successful in vitro differentiation to cartilage-like and IVD-like phenotype are using three dimensional (3D) and hypoxic cultures (Stoyanov et al., 2011).

Three dimensional cultures provide larger 3D surface for cellular attachment, protection against mechanical stresses and simulation of in vivo environment. Different biomaterials have been investigated and agarose hydrogels (Huang et al., 2004), poly-lactic-co-glycolic acid (PLGA) (Chung et al., 2008), atelocollagen (Sakai et al., 2006), alginate beads (Stoyanov et al., 2011), fibrin microbeads (Gorodetsky et al., 2011), collagen (Bertolo et al., 2012), synthetic polymers and other biomaterials (Martin et al., 2011) have shown to support cells, enhancing cell-cell and cell-matrix interactions. Main problems of rigid systems might be: (i) the way of delivery in vivo and (ii) the subsequent extrusion by the loaded IVD. 
On the other hand, gel-like materials lack some features of rigid matrices, for instance slower degradation time (Malda and Frondoza, 2006). Microcarriers might be an appropriate compromise between the two types, maintaining injectability while providing good cell support and delayed resorption. Microcarrier preparation can vary depending on the material and physical parameters such as shape, porosity and stiffness. Commercially available microcarriers have densities between 1.02 and $1.10 \mathrm{~g} / \mathrm{cm}^{3}$ (Malda and Frondoza, 2006). In terms of composition, collagen as a main constitutent of the IVD with a mass density estimated between 1.19 (hydrated) and $1.34 \mathrm{~g} /$ $\mathrm{cm}^{3}$ (dehydrated) seems to be a suitable biomaterial for microcarriers (Sart et al., 2013) in the treatment of DDD.

Not only mechanical, but also biochemical influences like hypoxia have been recognised to affect MSC chondrogenesis. In bone marrow the physiological level of oxygen ranges between $0 \%$ and $4 \%$ (Ivanovic, 2009). In vivo measurement of canine nucleus pulposus (the inner part of IVD), showed oxygen levels between $0.6 \%$ and $1.2 \%$ (Ejeskar and Holm, 1979). Oxygen levels of $1 \%$ (Ishihara and Urban, 1999), 2 \% (Felka et al., 2009), $3 \%$ (Ishihara and Urban, 1999), 5 \% (Purmessur et al., 2011) and $10 \%$ (Ishihara and Urban, 1999) have been tested for MSC, IVD cells (Allon et al., 2012; Yang et al., 2011) and articular chondrocytes (Schrobback et al., 2012; Scotti et al., 2012) to disclose their effects on proliferation and differentiation.

Here, we tested if microcarriers - made of collagen type I - are suitable supports for differentiation of bone marrowderived MSC to chondrogenic IVD-like phenotype in three dimensional cultures. The developed method for the production of microcarriers from solid collagen foam was further optimised by implementing hypoxic and dynamic conditions to aid the differentiation of MSC cultures. The results were assessed by analysing cell proliferation and expression of extracellular matrix proteins specific to IVD, namely collagen type I, collagen type II and proteoglycans.

\section{Materials and Methods}

\section{MSC Isolation and Culture}

Fresh bone marrow (BM) samples $(20 \mathrm{~mL})$ were obtained from the iliac crest of the donors during surgery, after informed consent and approval by the ethics committee of canton Lucerne (study number 730). MSC were isolated from BM of seven donors (average age: $49 \pm 9$ years) and split in two groups: cells from four donors were used to compare MSC chondrogenesis between passage 0 (P0) and 2 (P2), while cells from three donors were used to assess the influence of different oxygen levels and types of cultures. Cells from this group were expanded for three passages (P3) in culture.

The BM aspirates were diluted in $15 \mathrm{~mL} 3.8 \%$ sodium citrate (Applichem - Axonlab, Baden, Switzerland) and $20 \mathrm{~mL}$ phosphate buffered saline (PBS, Applichem) and then filtered through a $100 \mu \mathrm{m}$ cell strainer (Falcon Faust, Schaffhausen, Switzerland) to remove blood clots. Mononuclear cells were separated by H-Lympholyte Cell
Separation Media gradient centrifugation (density $1.077 \mathrm{~g} /$ mL; Cedarlane - Bio Concept, Allschwil, Switzerland) in a Leucosep tube (Huberlab, Reinach, Switzerland) at $800 \times g$ for $15 \mathrm{~min}$, washed with PBS, centrifuged again at $210 \times g$ for $10 \mathrm{~min}$, re-suspended in PBS and counted using trypan blue dye in a single use Neubauer chamber (C-Chip Typ Neubauer, Zeiss, Feldbach, Switzerland). Cells were plated in tissue culture flasks (TPP - Faust) in non-haematopoietic (NH) Stem Cell Media (Miltenyi, Bergisch Gladbach, Germany) at $37{ }^{\circ} \mathrm{C}$ in a humid atmosphere containing $5 \% \mathrm{CO}_{2}$ and $21 \% \mathrm{O}_{2}$. After 2 days, non-adherent cells were discarded, whereas adherent cells were cultured in growing medium consisting in DMEM/ F12 + GlutaMAX, supplemented with $10 \%$ foetal bovine serum (FBS), (100 units $/ \mathrm{mL})$ penicillin / (100 mg/mL) streptomycin, $2.5 \mu \mathrm{g} / \mathrm{mL}$ Amphotericin B (all Gibco LuBioScience GmbH, Lucerne, Switzerland) and $5 \mathrm{ng} /$ $\mathrm{mL}$ recombinant basic Fibroblast Growth Factor (bFGF, Peprotech - LuBioScience) with medium changed 3 times a week.

\section{Microcarrier preparation}

The material used to prepare microcarriers was a spongeshaped medical device for human use, designed as a wound dressing and made of pure, native and structurally unaltered collagen type I, derived from equine flexor tendon (Biopad, Euroresearch, Milan, Italy). The product is non-toxic, biocompatible and completely bioabsorbable in vivo. Preparation of fibrous microcarriers particles was achieved by homogenisation in Dispomix Drive system (Miltenyi) of collagen sponge pad soaked in PBS (Fig. 1A). Collagen was triturated to particles and the resulting dispersion presented microcarriers of different shapes and sizes, the majority ranging between 100 and 1,500 $\mu \mathrm{m}$.

To characterise the particle sizes (Fig, 1B), pictures of the microcarrier suspension were taken with a stereomicroscope (Olympus Schweiz AG, Volketswil, Switzerland) and analysed using the iTEM software (Olympus). Due to the heterogeneity in shapes, the parameters used to assess the size of the microcarriers were the width and the length of each fragment (500 particles were measured in total).

Microcarriers could be injected using a $22 \mathrm{G}$ needle $(0.72 \mathrm{~mm})$ in intact and digested bovine IVD (Fig.1C). The inner part of the bovine IVD (nucleus pulposus) was previously digested by injection of papain $(120 \mathrm{U} / \mathrm{mL}$, Sigma - Fluka Chemie GmbH, Buchs, Switzerland) and incubated for three days at $37^{\circ} \mathrm{C}$ (protocol adapted from Malonzo et al., 2013). Microcarriers used to track intradisc distribution (in intact and digested discs) were stained blue with colloidal Coomassie stain (Applichem) and then washed multiple times until no stain was eluted.

\section{Microcarriers as a support for MSC culture}

Microcarriers were used as a support for cellular growth and chondrogenic differentiation. Cell attachment to scaffolds was promoted by incubating cell suspension with microcarriers in non-adherent propylene tubes with twosteps closing cap (Falcon), allowing gas exchange. Varying the amount of collagen microcarriers we showed the optimal 
Fig. 1. Schematic representation of microcarrier preparation (A). Before cell seeding, collagen pads were triturated in Dispomix devices to small and heterogeneous fragments ideal for cell support (scale bar of $1 \mathrm{~mm}$ ). Microcarrier suspension was examined by light microscopy and the widths and lengths of particles were measured using the iTEM software (B). Results of the analysis are shown in the graphs. Injectability of microcarriers (stained in blue) was proven in bovine intervertebral discs (IVD) (C). Only a small fraction of microcarriers could be injected in the healthy disc (left picture), due to its compact structure, while in the papain digested IVD the injected amount of microcarrier suspension was larger (right picture).

Fig. 2. MSC seeded on microcarriers were stained (B) after two days in culture with SYBR green (Fluorescein isothiocyanate (FITC) on the top, FITC-phase contrast at the bottom; scale bar corresponds to $100 \mu \mathrm{m}$ ). The optimal ratio between cells and collagen (A) was determined by comparing the mean cell number on microcarriers after seven days in growing medium. The red line indicates the starting number of cells (40,000).
A

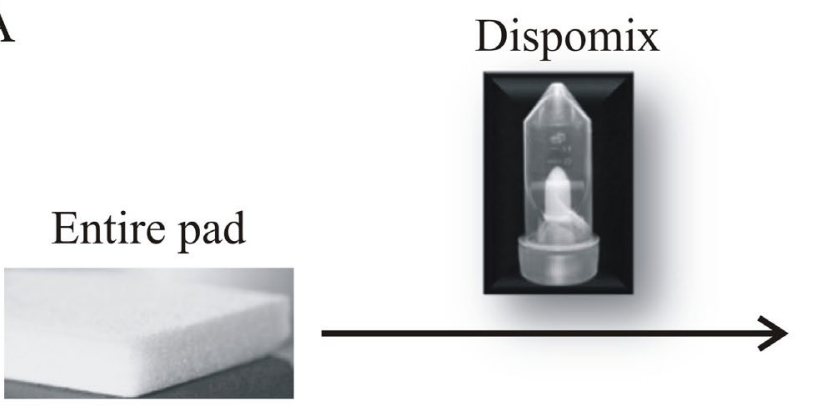

Microcarriers

B
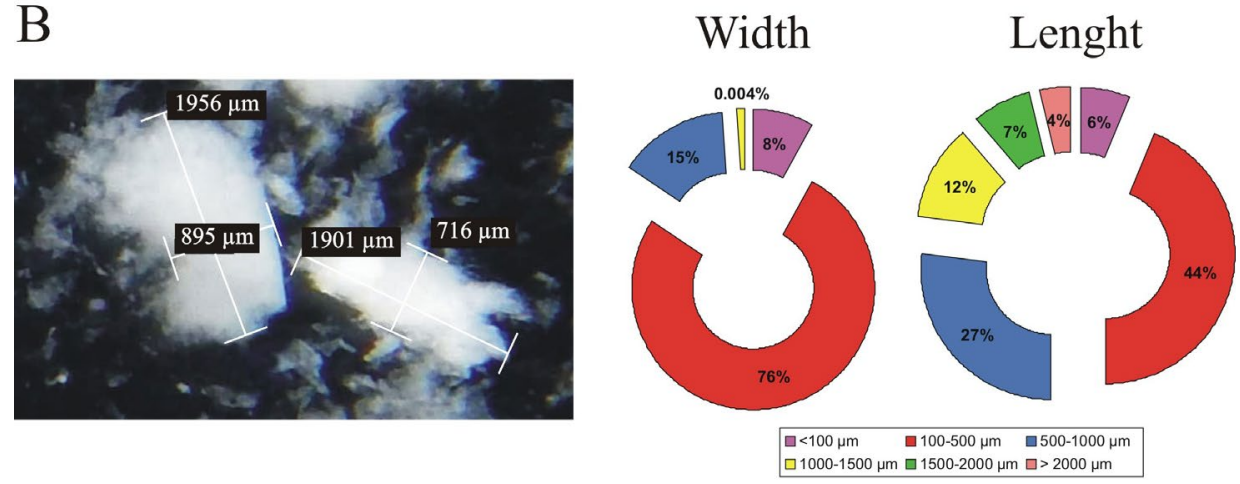

C

Healthy disc

Digested disc
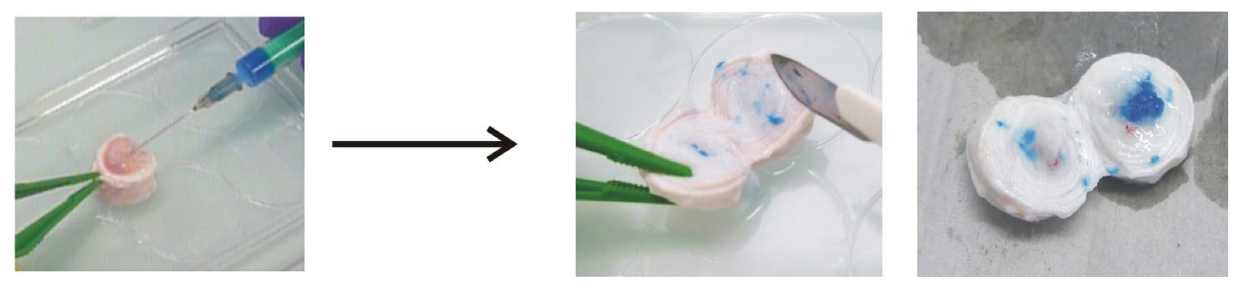

A

B

\section{Collagen / MSC ratio}
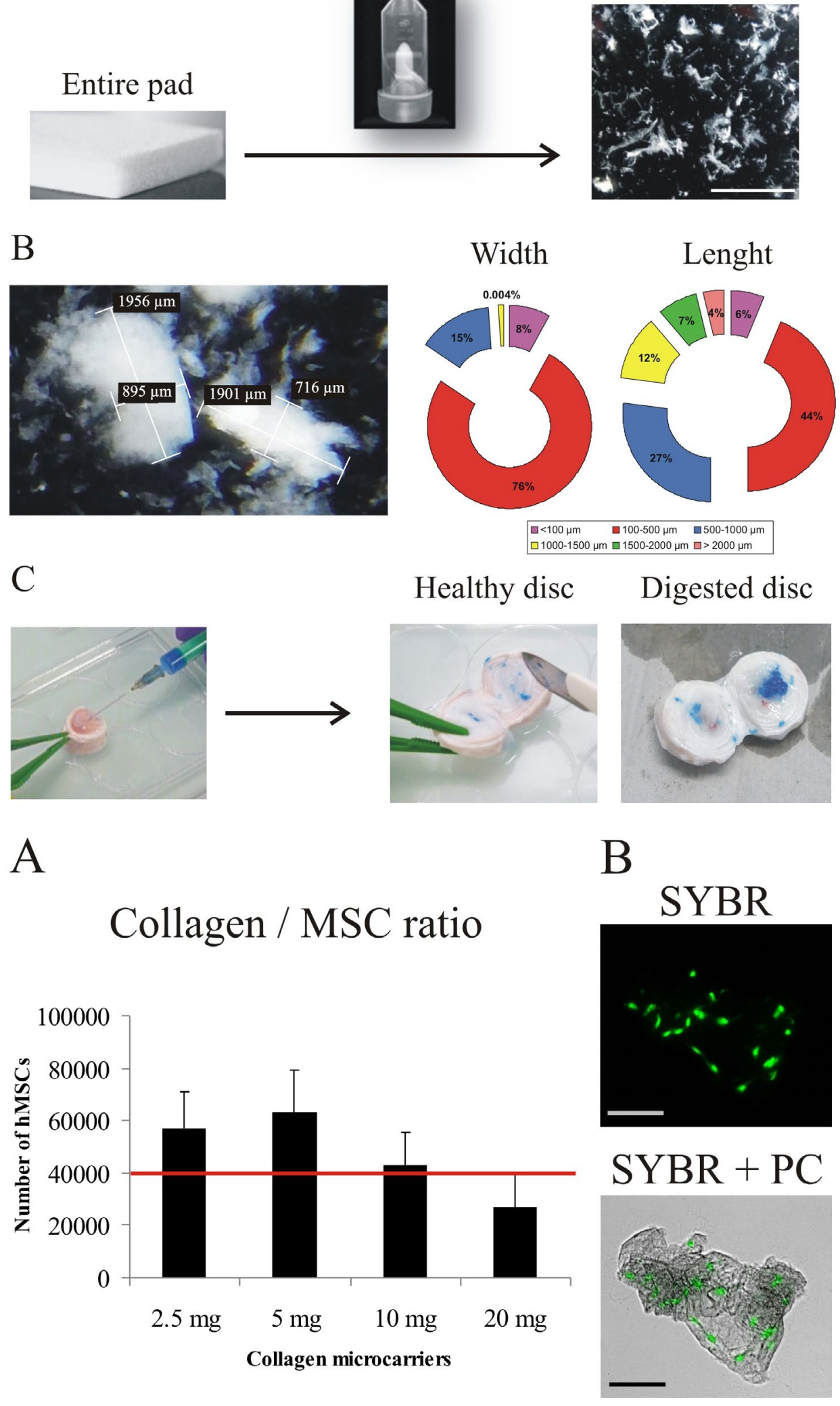

Lenght ratio between cells and collagen to be $4 \times 10^{4}$ cells $/ 5 \mathrm{mg}$ collagen (Fig 2A), which was used in further experiments involving cells at P2 and P3. Freshly isolated cells from bone marrow $(\mathrm{P} 0)$ were seeded on microcarriers at the density of $2 \times 10^{6}$ cells $/ 5 \mathrm{mg}$ collagen. Additionally, MSC colonisation was investigated by fluorescence microscopy after two days of culture in growing medium at $21 \% \mathrm{O}_{2}$ (Fig.2B). Microcarrier particles were randomly separated in a 8-well chamber slide (Lab-TekII, Sigma), washed with PBS and fixed by pure methanol (Applichem). After three washing cycles, cell-microcarrier particles were stained with $0.01 \%$ SYBR green (Invitrogen - LuBioScience 
$\mathrm{GmbH}$, Lucerne, Switzerland) solution (1:10,000 in $\left.\mathrm{dH}_{2} \mathrm{O}\right)$ and examined by fluorescence microscopy (Fluorescence Microscope U-TB190, Olympus).

\section{Dynamic cultures}

Dynamic cultures were performed using a tube roller mixer (RM 5-4, Huberlab) placed inside the incubator. Falcon tubes (with two-steps closing cap, allowing gas exchange) containing MSC-microcarriers were submitted to constant rotation around the longitudinal axis. Tubes were modified by applying a rubber washer on the outside, which created a tilt against media spills. In proliferation and differentiation assays, the tubes rotated 3 times per minute.

\section{Chondrogenic cultures}

To induce chondrogenesis, MSC-microcarriers were expanded for seven days in normoxia to allow optimal spreading of cells on scaffolds, and then maintained for 21 days in chondrogenic medium (either $21 \%$ or $5 \%$ $\mathrm{O}_{2}$ ). Chondrogenic medium consisted of DMEM/F12 + GlutaMAX, supplemented with $2.5 \%$ FBS, 40 ng/ $\mathrm{mL}$ dexamethasone (Applichem), $50 \mu \mathrm{g} / \mathrm{mL}$ ascorbate2-phosphate (Sigma), $50 \mu \mathrm{g} / \mathrm{mL}$ L-proline (Sigma), $100 \mathrm{U} / \mathrm{mL}$ penicillin, $100 \mathrm{mg} / \mathrm{mL}$ streptomycin, $2.5 \mu \mathrm{g} /$ $\mathrm{mL}$ Amphotericin B, $10 \mu \mathrm{g} / \mathrm{mL} 1 \mathrm{X}$ Insulin, $5.5 \mu \mathrm{g} / \mathrm{mL}$ Transferrin, $0.67 \mathrm{ng} / \mathrm{mL}$ Selenium X Supplement (ITS, Gibco) and $10 \mathrm{ng} / \mathrm{mL}$ transforming growth factor- $\beta 1$ (TGF- $\beta 1$ ) (Peprotech). All media was replaced three times per week.

\section{Cell counting and metabolic activity assay}

Quantitative determination of cell number on microcarriers was carried out by PrestoBlue ${ }^{\mathrm{TM}}$ (Invitrogen) cell viability indicator. PrestoBlue ${ }^{\mathrm{TM}}$ reagent was used according to the manufacturer's instructions and the following protocol. PrestoBlue ${ }^{\mathrm{TM}}$ reagent was added to samples (1:10 dilution), incubated for $1 \mathrm{~h}$ at $37^{\circ} \mathrm{C}$ and fluorescence intensity was quantified by a multimode detector (DTX 880, Beckman Coulter, Nyon, Switzerland) at $595 \mathrm{~nm}$. Results referred to a standard curve, previously prepared with cells derived from the same donor and under the same conditions.

\section{Immunohistological analysis}

Immunohistochemical analysis was used to detect aggrecan, collagen type I and type II accumulation. Constructs were harvested at 21 days of culture in chondrogenic medium, embedded in OCT TissueTek compound (Sakura - Sysmex Suisse AG, Horgen, Switzerland) for $30 \mathrm{~min}$, frozen at $-80^{\circ} \mathrm{C}$ and subsequently sectioned at $20 \mu \mathrm{m}$ using a cryostat (Microm HM560, Histocom AG, Zug, Switzerland).

Endogenous peroxidase was quenched by $3 \% \mathrm{H}_{2} \mathrm{O}_{2}$ in PBS at room temperature, and washed with PBS. Before incubation with anti-collagen type II antibody, sections were pre-treated with 2,500 U/mL hyaluronidase (Sigma) in PBS at $37^{\circ} \mathrm{C}$, while sections for immunodetection with antiaggrecan antibody were pre-treated with chondroitinase ABC $(0.25 \mathrm{U} / \mathrm{mL}$, Sigma $)$ in $0.1 \mathrm{M}$ Tris $0.03 \mathrm{M}$ acetate buffer $\mathrm{pH} 6.5$, at $37{ }^{\circ} \mathrm{C}$. Non-specific background was blocked with PBS containing $1 \mathrm{mg} / \mathrm{mL}$ BSA, $10 \%$ FBS and $0.1 \%$ Triton (Applichem) followed by overnight incubation at $4{ }^{\circ} \mathrm{C}$ with monoclonal mouse antibodies against collagen type I (1:20; M-38, Development Studies Hybridoma Bank (DSHB), University of Iowa, Iowa City, IA, USA), collagen type II (1:20; II-II6B3, DSHB) and aggrecan (1:10,000; AHP0022, Biosource-LuBioScience) in blocking solution. After washing with PBS, sections were incubated with a secondary biotinylated goat antimouse antibody (1:200; B0529, Sigma), and then with streptavidin-horseradish peroxidase $(1: 200 ; \mathrm{S} 2438$, Sigma) at room temperature. Aggrecan, collagen type I and type II were visualised by reaction with $0.075 \%$ solution of 3-amino-9-ethylcarbazole (AEC, Applichem) in $0.01 \% \mathrm{H}_{2} \mathrm{O}_{2}$. Sections were mounted with $70 \%$ Glycerol (Applichem) and examined by light microscopy (Olympus).

Histological detection of sulphated glycosaminoglycan (GAG) accumulation was carried out by Alcian Blue staining. Sections were stained overnight with $0.4 \%$ alcian blue (Fluka - Sigma) dissolved in $0.01 \% \mathrm{H}_{2} \mathrm{SO}_{4}$ and $0.5 \mathrm{M}$ guanidine hydrochloride (Fluka - Sigma). Next, sections were washed for $30 \mathrm{~min}$ in $40 \% \mathrm{DMSO}$ and $0.05 \mathrm{M} \mathrm{MgCl}_{2}$. Finally, sections were mounted with $70 \%$ glycerol and examined by light microscopy. Cell distribution on microcarriers was visualised by Giemsa (Applichem) staining. Sections were firstly fixed in pure methanol, washed in PBS and incubated with Giemsa staining solution. Prior to examination by light microscopy, excess of Giemsa solution was removed by abundant washes in $\mathrm{dH}_{2} \mathrm{O}$.

Table 1. Human genes used in quantitative RT-PCR.

\begin{tabular}{|l|l|c|}
\hline \multirow{2}{*}{ Gene } & Primer nucleotide sequence $(\mathbf{5}, \boldsymbol{\rightarrow} \mathbf{3})$ & Amplicon (bp) \\
\hline \multicolumn{2}{|l|}{ Housekeeping gene } & \\
\hline \multirow{2}{*}{ GAPDH } & F - TGGACTCCACGACGTACTCA & 102 \\
\cline { 2 - 3 } & R - GGAAGCTTGTCATCAATGGAA & \\
\hline \multirow{2}{*}{ Chondrogenic Differentiation marker } & \\
\hline \multirow{2}{*}{ Collagen Type I } & F - CCTCCTGGCTCTCCTGGT & 106 \\
\cline { 2 - 3 } & R - AGGGAGACCGTTGAGTCCAT & \\
\hline \multirow{2}{*}{ Collagen Type II } & F - GAAGTGCTGGTGCTCGTG & 125 \\
\cline { 2 - 3 } & R - GGCCTCTCCTTGCTCACC & \\
\hline \multirow{2}{*}{ Aggrecan } & F - AGGCTATGAGCAGTGTGAACG & 125 \\
\cline { 2 - 3 } & R - GCACGCCATAGGTCCTGA & \\
\hline
\end{tabular}

( $\mathrm{F}=$ Forward, $\mathrm{R}=$ Reverse. $\mathrm{bp}=$ base pairs $)$. 
A

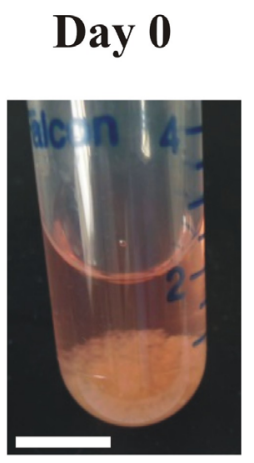

$\mathrm{B}$

\section{Day 21}

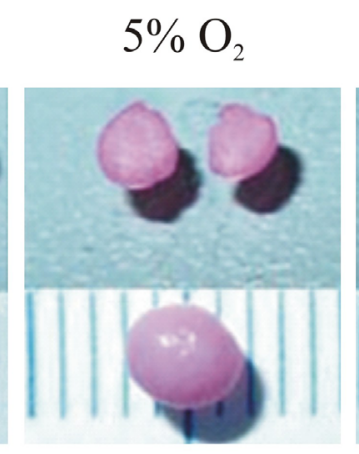

$2 \% \mathrm{O}_{2}$
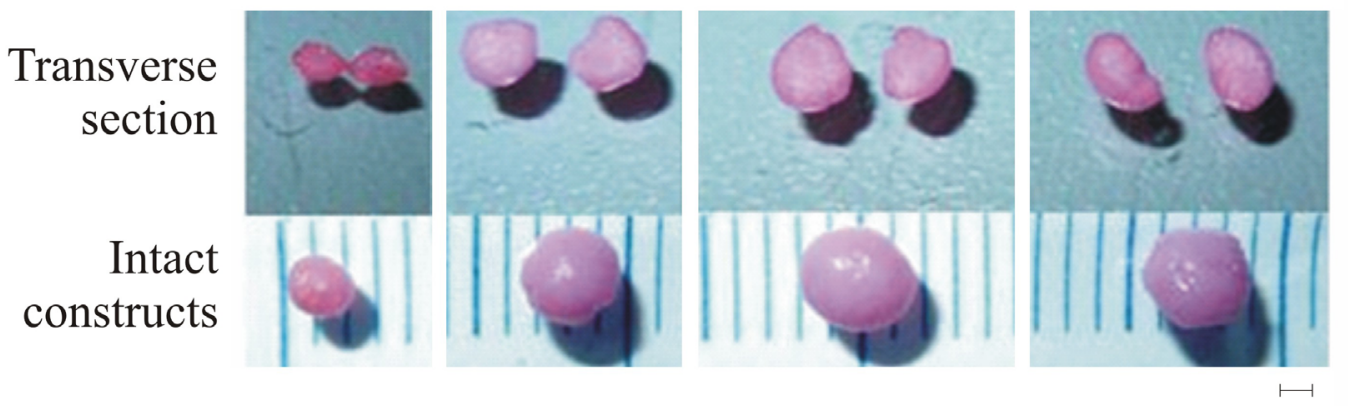

$1 \mathrm{~mm}$

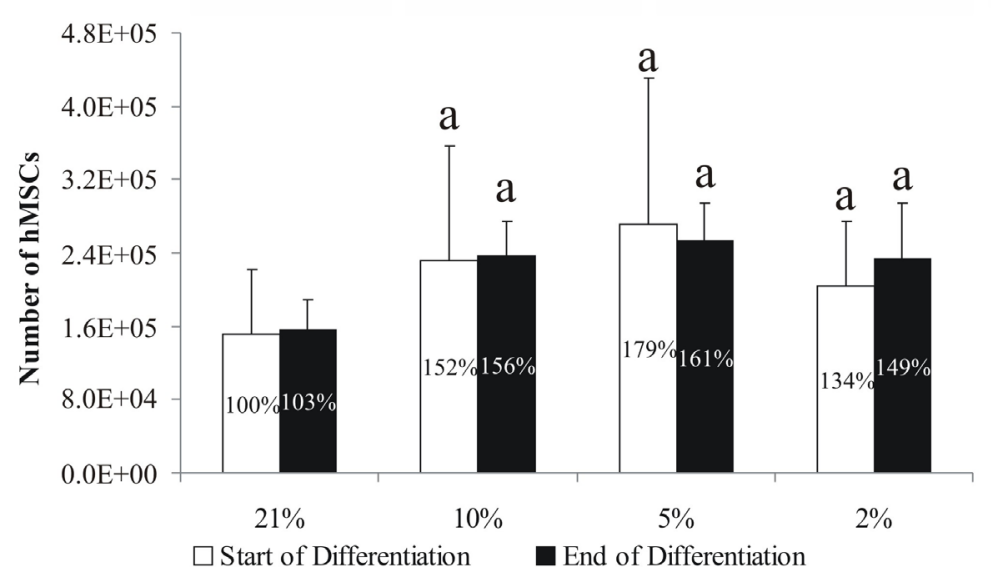

Fig. 3. Images of MSC-constructs after $21 \mathrm{~d}$ of chondrogenic differentiation at different levels of oxygen (A): $21 \%$ (normoxic control), $10 \%, 5 \%$ and $2 \%$ (scale bar is $1 \mathrm{~mm}$ ). On the left, an image of microcarriers at the beginning of the assay. MSC-constructs are shown transversely sectioned (upper row) and intact (lower row). The number of cells per MSC-construct from each type of culture was determined at the beginning and at the end of the differentiation period (B). $(n=3$; The number of cells per construct is represented as a mean $\pm \mathrm{SD}$ and compared to the number of cells at the beginning of differentiation in $21 \% \mathrm{O}_{2}$ level, $\mathbf{a}=p<0.05$ ).

RNA Isolation, cDNA Synthesis and Real Time PCR Total RNA was isolated from MSC-microcarrier constructs after 21 days in culture. Constructs were homogenised using Dispomix in RNA lysis buffer of Aurum Total Mini Kit (Bio Rad, Reinach, Switzerland), following the manufacturer's instructions with the modification of adding $2 \mu \mathrm{L}$ polyacryl carrier (LucernaChem, Lucerne, Switzerland) in the kit lysis buffer. cDNA was prepared using VILO cDNA Synthesis Kit (Invitrogen).

Real-time (RT)-PCR reactions were carried out in triplicates with the primers listed in Table 1 at a concentration of $250 \mathrm{nM}, 5 \mu \mathrm{L}$ cDNA template, and IQ SYBR Green Supermix (Bio Rad). Specific products were amplified by a quantitative PCR system (CFX96 ${ }^{\mathrm{TM}}$ Real Time System, Bio Rad). Real-time PCR was carried out with the following settings: denaturation $95^{\circ} \mathrm{C}, 3 \mathrm{~min}$ (1 cycle); $95{ }^{\circ} \mathrm{C}, 15 \mathrm{~s} ; 64{ }^{\circ} \mathrm{C}, 20 \mathrm{~s}$ and $72{ }^{\circ} \mathrm{C}, 20 \mathrm{~s}(40$ amplification cycles). PCR reactions were carried out in triplicate in a final volume of $25 \mu \mathrm{L}$ in 96-well plates (Bio Rad). Melting curve analysis was performed after each reaction. Gene expression differences were determined using the $2^{-\Delta \Delta \mathrm{Ct}}$ method and the results were normalised to the expression of GAPDH.

\section{Statistical Analysis}

Data were expressed as the mean \pm SD. Non-parametric Mann-Whitney-Wilcoxon U test for dependent variables was used to determine significant differences between samples, as a normal distribution of the data could not be guaranteed in this data set. For all tests, $p<0.05$ was considered significant. Data analysis was performed with SPSS 14.0 for Windows (SPSS Inc.).

\section{Results}

Size and shape analysis of microcarrier particles

Observations under a stereomicroscope of microcarrier particles showed fragments of frayed appearance, very heterogeneous in shape and size (Fig. 1B). The picture shows a schematic example of microcarrier examination of the widths and lengths $(n=500)$. As represented 
A
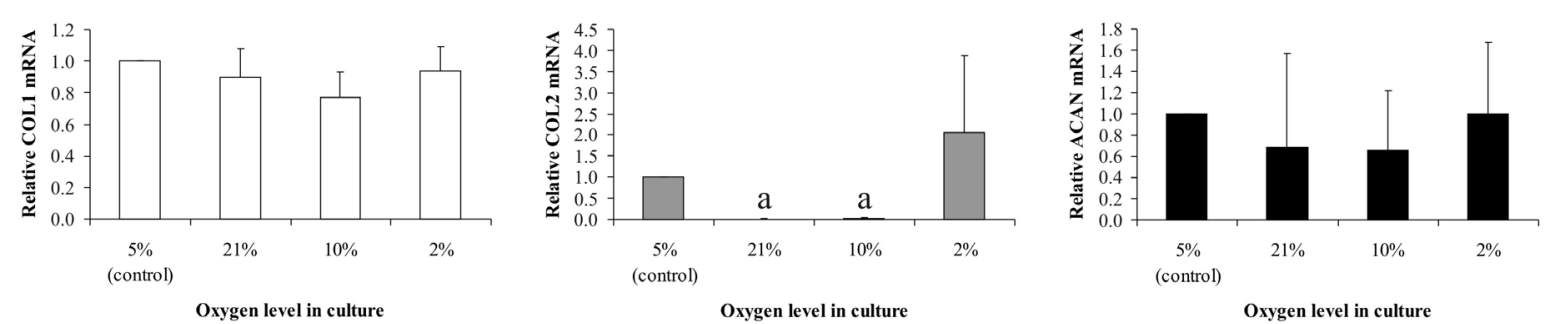

B $21 \% \mathrm{O}_{2} \quad 5 \% \mathrm{O}_{2}$

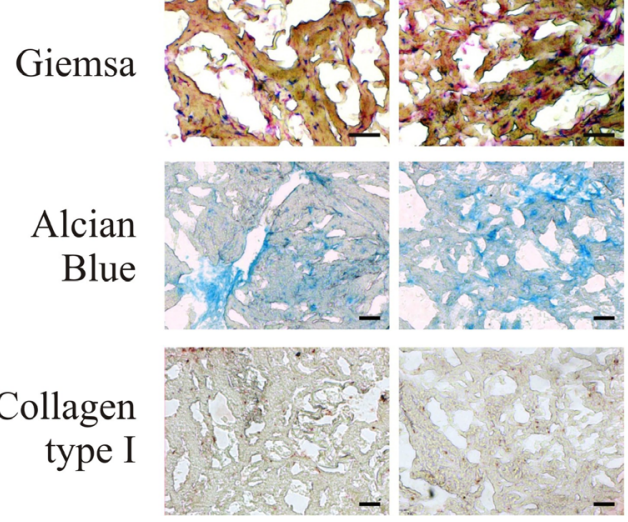

\section{Collagen type II}

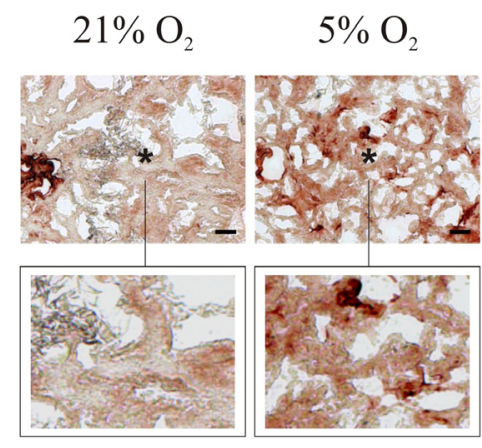

Aggrecan

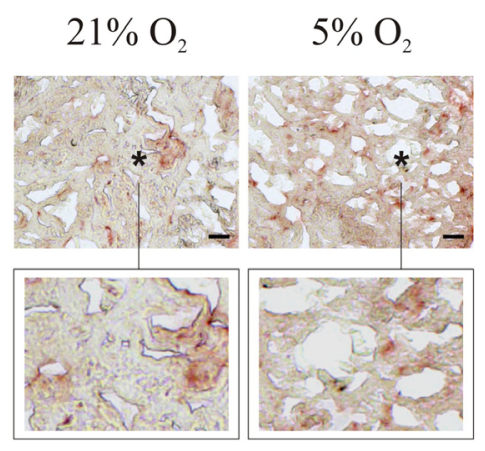

Fig. 4. Effects of oxygen levels on extracellular matrix accumulation after MSC differentiation was determined by gene expression (A) and immunohistochemistry (B). Gene expression of collagen type I, type II and aggrecan by MSC-microcarriers after $21 \mathrm{~d}$ of chondrogenic culture. $(n=3$; Gene expression was normalised to GAPDH and compared to expression in $5 \%$ oxygen; data are represented as a mean $\pm \mathrm{SD}, \mathbf{a}=p<0.05$ ). Localisation of cells stained by Giemsa (nuclei in blue and cytoplasm in pink) was proved on sections of MSC-microcarriers cultured at $21 \%$ (as a control, on the left) and $5 \%$ (on the right) oxygen levels, as well as deposition of proteoglycan-rich extracellular matrix by alcian blue staining (upper rows of the left panel). Immunohistochemistry microphotographs show deposition of collagen type I (bottom row, left panel), collagen type II and aggrecan (panels on the right, with the respective magnifications below) by positive red-coloured signal (scale bar is $100 \mu \mathrm{m}$ ).

in the graphs, six dimensional ranges were identified: $<100 \mu \mathrm{m} ; 100-500 \mu \mathrm{m} ; 500-1,000 \mu \mathrm{m} ; 1,000-1,500 \mu \mathrm{m}$; $1,500-2,000 \mu \mathrm{m} ;>2,000 \mu \mathrm{m}$. The smallest width of the microcarriers was $48 \mu \mathrm{m}$ and the longest was $1,249 \mu \mathrm{m}$, while the smallest length was $50 \mu \mathrm{m}$ and the longest $2,876 \mu \mathrm{m}$. Microcarriers widths greater than $1,500 \mu \mathrm{m}$ were not found, and only $0.004 \%$ of the particles measured were in the range $1,000-1,500 \mu \mathrm{m}$. The majority of microcarrier widths were comprised in the range 100-500 $\mu \mathrm{m}$ (44 \%), as well as the lengths ( $77 \%$ ).

\section{MSC number and morphology in microcarriers are positively influenced by hypoxia}

After 21 days in chondrogenic culture, MSC-microcarriers fused together forming a single construct, as opposed to day 0 where MSC-microcarriers were unbound (Fig. 3A). Depending on culture conditions, constructs were characterised by diverse sizes: compared to $21 \%$ oxygen culture (normoxic control), constructs at $10 \%, 5 \%$ and $2 \%$ oxygen levels were larger. Construct in normoxia had a size of approximately $2 \mathrm{~mm}$ diameter, against the 3.5$4 \mathrm{~mm}$ of the constructs in hypoxia.

This difference in size correlated to the number of cells retained within constructs (Fig. 3B). At the beginning of the differentiation assay (after one week) cell proliferation was significantly higher in the microcarriers cultured in hypoxic environment. Compared to normoxia $(\sim 150,000$ cells), the increase in cell number corresponded to $152 \%$ $(\sim 230,000$ cells $)$ in $10 \%$ oxygen $(p<0.05), 179 \%$ $(\sim 260,000$ cells $)$ in $5 \%$ oxygen $(p<0.05)$ and $134 \%$ $(\sim 200,000$ cells $)$ in $2 \%(p<0.05)$ oxygen. Similarly, at the end of differentiation (three weeks), the number of cells per culture was significantly higher under hypoxic conditions compared to normoxic, and the relative amount of cells was equivalent to the beginning of the differentiation assay.

\section{Hypoxia upregulates collagen type II expression in MSC-microcarriers}

After 21 days in culture, quantitative real-time PCR was used to assess expression of the most important extracellular matrix molecules of the IVD, namely collagen type I (COL1) and type II (COL2), and aggrecan (ACAN) by MSC on microcarriers (Fig. 4A). Expression of COL 1 and ACAN by MSC in $5 \%$ oxygen culture was comparable to other culture conditions and results showed no differences. Oxygen at $5 \%$ and $2 \%$ levels promoted the expression of COL 2 , especially in $2 \%$ hypoxia where the expression increased twofold, while COL2 expression 
A

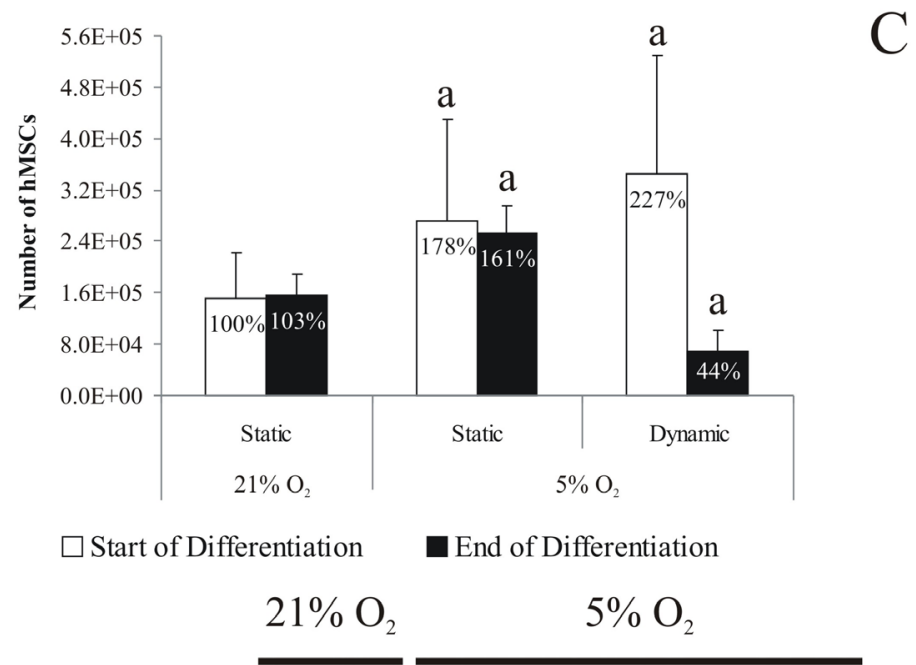

B

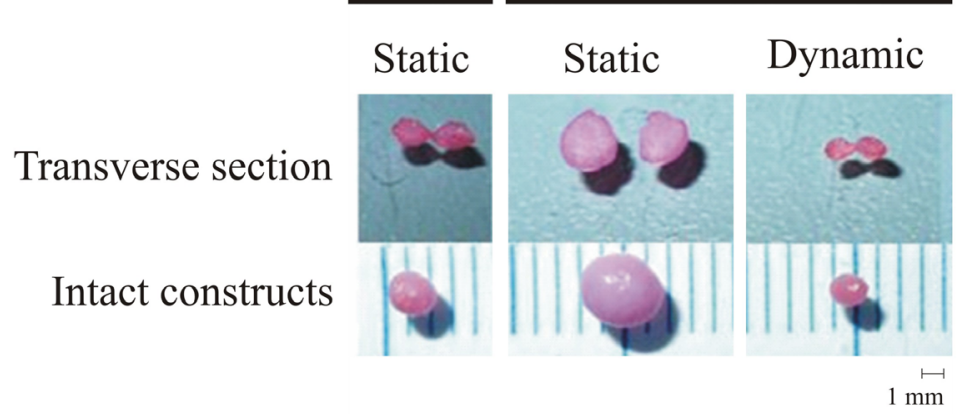

Dynamic
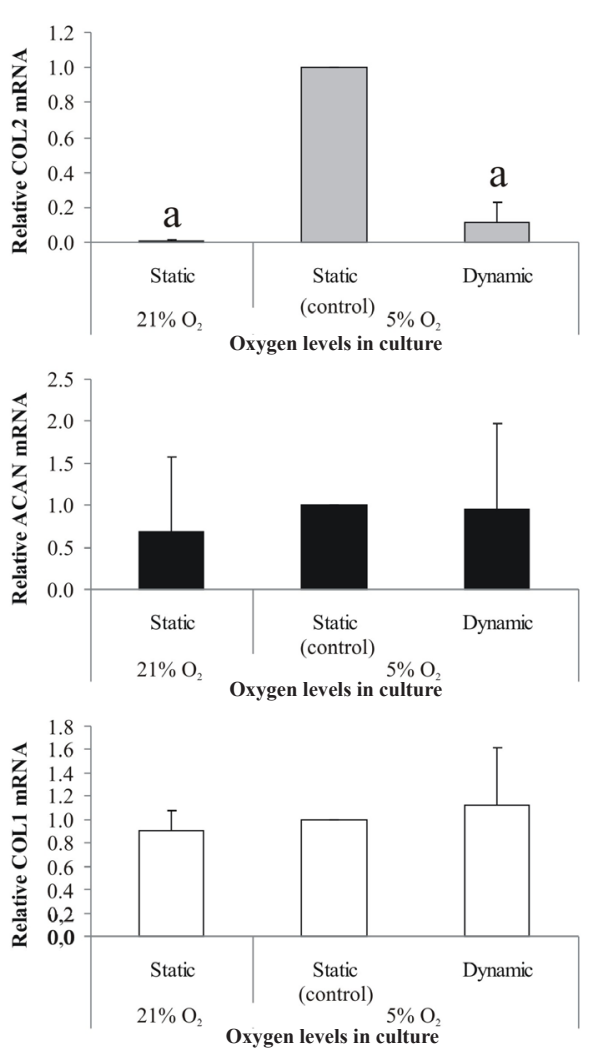

Fig. 5. Analysis of MSC-constructs after $21 \mathrm{~d}$ of chondrogenic differentiation at different levels of oxygen, $21 \%$ and $5 \%$, in static and dynamic cultures. The number of cells per MSC-construct from each type of culture was determined at the beginning and at the end of the differentiation period (A). $(n=3$; The number of cells per construct is represented as a mean $\pm \mathrm{SD}$ and compared to the number of cells at the beginning of differentiation in $21 \% \mathrm{O}_{2}$ level and static culture, $\mathbf{a}=p<0.05$ ). MSC-constructs are shown transversely sectioned (upper row) and intact (lower row; scale bar is $1 \mathrm{~mm})(\mathbf{B})$. Gene expression of collagen type II, aggrecan and collagen type I by MSC-microcarriers after $21 \mathrm{~d}$ of chondrogenic culture $(\mathbf{C})$ in the different samples. $(n=3$; Gene expression was normalised to GAPDH and compared to expression in $5 \%$ oxygen and static culture; data are represented as a mean $\pm \mathrm{SD}, \mathbf{a}=p<0.05$ ).

was almost undetectable in normoxia and $10 \%$ oxygen groups $(p<0.05)$.

Cells were homogenously spread in the constructs under both normoxic and hypoxic $\left(5 \% \mathrm{O}_{2}\right)$ conditions as shown by Giemsa staining (Fig. 4B). MSC-constructs in $5 \%$ oxygen culture accumulated more proteoglycan compared to normoxia as evaluated by histological staining of construct sections with alcian blue for proteoglycan (GAG) accumulation. The localisation of collagen type I, collagen type II and aggrecan was determined by immunostaining, which showed that in MSC-constructs differentiated in $5 \%$ hypoxia, collagen type II and aggrecan accumulation was undoubtedly higher than in normoxia, while the amount of collagen type I staining showed similar intensity between the two groups. The signal intensity of collagen type II was higher compared to that of aggrecan.

\section{Dynamic cultures promote cell proliferation on microcarriers, but inhibit chondrogenesis}

Dynamic culture had a beneficial impact on cell proliferation, before differentiation assay (Fig. 5A). After one week, the number of cells retained in MSC-microcarriers cultured in $5 \%$ hypoxia was $178 \%(\sim 250,000$ cells, $p<0.05)$ compared to normoxia ( $\sim 150,000$ cells $)$, and cell number was further increased to $227 \%(\sim 340,000$ cells, $p<0.05)$ in dynamic culture. Effects of dynamic cultures on chondrogenic differentiation of MSC-microcarriers in $5 \%$ hypoxia culture were compared to static cultures in both $5 \%$ hypoxia and normoxia. After $21 \mathrm{~d}$ of differentiation, MSC-microcarrier aggregates had dissimilar sizes depending on culture condition, for example under static condition, aggregate in hypoxia was double the size in comparison to normoxia (4 $\mathrm{mm} \mathrm{vs.} 2 \mathrm{~mm}$ diameter) (Fig. 5B). However, when MSC-microcarriers were differentiated under dynamic conditions, the increase in size seen in static hypoxic culture was hindered and the aggregates had sizes similar to those seen in normoxia. At the end of differentiation, cell number was unchanged in the static cultures compared to the beginning, while in dynamic culture cell number dropped fourfold - down to $44 \%(\sim 80,000$ cells, $p<0.05)$ - reflecting the differences observed in construct sizes.

Dynamic cultures affected also gene expression of MSC-microcarriers at the end of differentiation (Fig. 
A

$\mathrm{B}$
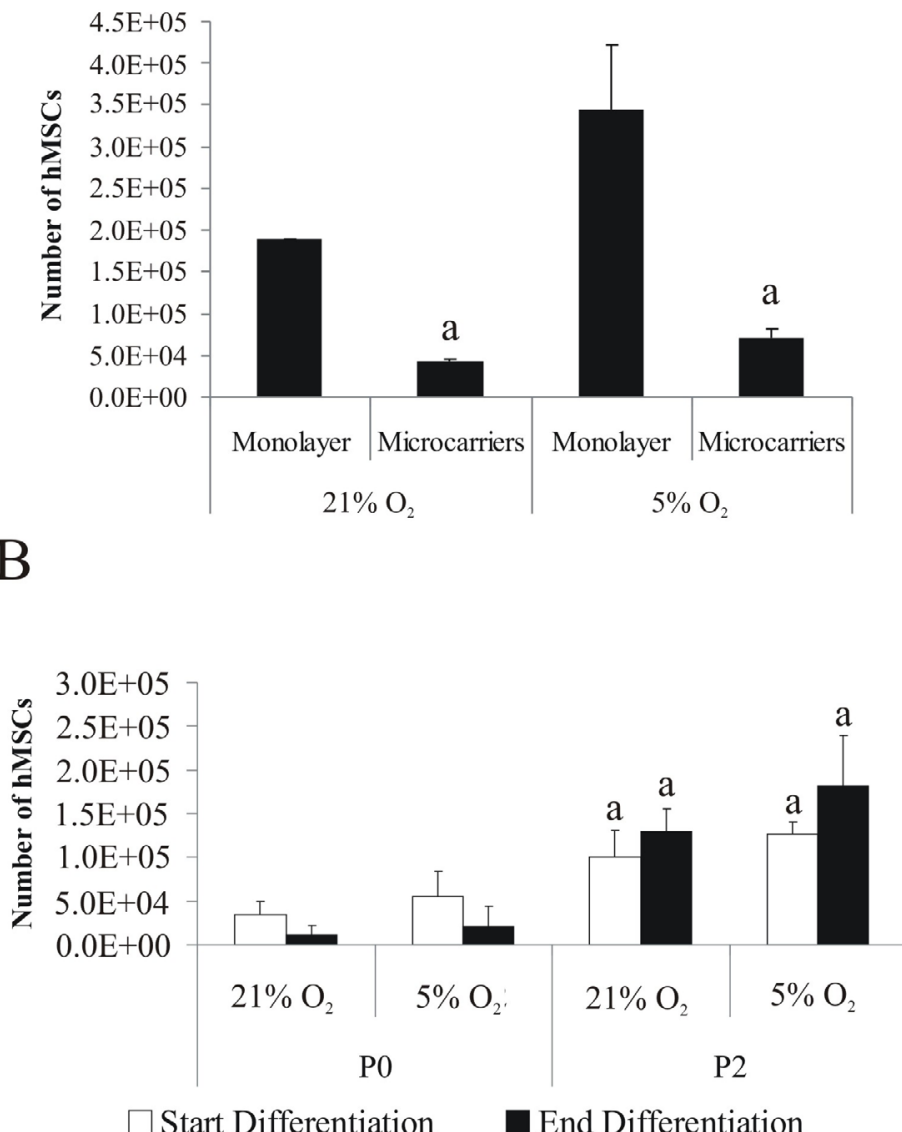
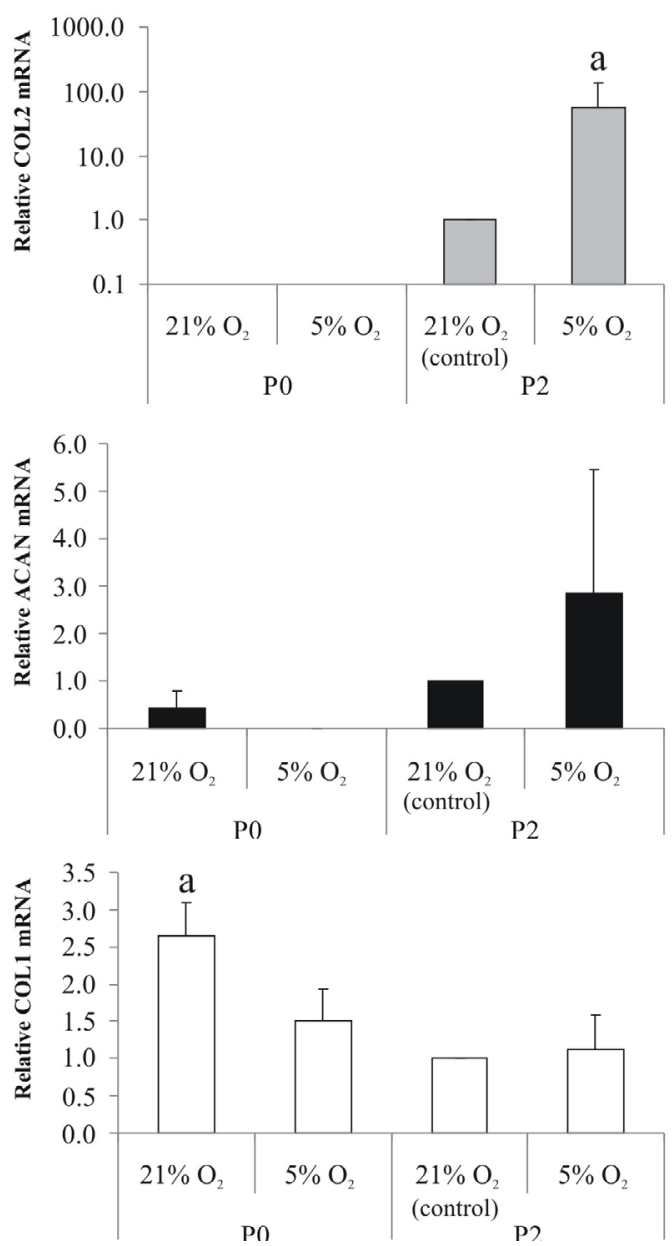

Fig. 6. Comparison of cell growing rate and differentiation potential between freshly isolated (P0) and early passage MSC (P2) on microcarriers and monolayers, at $21 \%$ and $5 \%$ oxygen level. Freshly isolated MSC were either plated in monolayer or microcarriers at $21 \%$ and $5 \%$ oxygen level (A), and cell number was determined after $14 \mathrm{~d}$ in culture $(p<0.05)$. Cell number was also determined at the start and end of differentiation of P0 and P2 MSC (B), at $21 \%$ and $5 \%$ oxygen level $(n=4$; the number of cells per construct is represented as a mean \pm SD and compared to the number of $\mathrm{P} 0$ cells at the beginning of differentiation in $21 \% \mathrm{O}_{2}$ level and static culture, $\mathbf{a}=p<0.05$ ). Gene expression of collagen type II, aggrecan and collagen type I by MSC at P0 and P2 after $21 \mathrm{~d}$ of chondrogenic culture (C) at $21 \%$ and $5 \%$ oxygen level. ( $n=4$; Gene expression was normalised to GAPDH and compared to expression of $\mathrm{P} 2 \mathrm{MSC}$ in $5 \%$ oxygen; data are represented as a mean $\pm \mathrm{SD}, \mathbf{a}=p<0.05$ ).

5C). Under static conditions, hypoxia strongly promoted expression of COL2, as opposed to normoxia $(p<0.05)$, but the advantageous effect of hypoxia was reversed under dynamic conditions where COL2 expression was again reduced $(p<0.05)$. Expression of ACAN and COL1 showed no changes between static and dynamic cultures.

\section{Comparison of freshly isolated (P0) and early passages (P2) MSC chondrogenic potential in normoxia and hypoxia}

Cell proliferation rates of freshly isolated mononuclear cells from bone marrow extracts in normoxia and $5 \%$ hypoxia were compared between microcarriers and monolayer cultures for $14 \mathrm{~d}$, (Fig. 6A). In monolayer, the number of MSC was significantly higher compared to microcarriers, independently of oxygen levels. In normoxia, the number of cells grown on microcarriers was only a quarter $(\sim 40,000$ cells $)$ of the number of cells in monolayer $(\sim 190,000$ cells, $p<0.05)$. Hypoxia increased cell number in both type of cultures but did not close the gap: cells in hypoxia were up to $38 \%(\sim 70,000$ cells, $)$ and in monolayer up to $183 \%(\sim 350,000$ cells, $p<0.05)$.

After one week in culture, MSC at P0 and P2 were seeded on microcarriers and differentiated for $21 \mathrm{~d}$ in normoxia and $5 \%$ hypoxia (Fig. 6B). Then at one week of differentiation, the number of MSC at P2 $(\sim 100,000$ cells) was threefold the number of cells at P0 (30,000 cells, $p<0.05)$. Hypoxia increased non-significantly cell number in both type of cultures up to $162 \%$ at P0 (55,000 cells) and $130 \%$ at $\mathrm{P} 2$ (130,000 cells). At the end of differentiation, cell number at P0 decreased to approximately one third of the amount of cells counted at the beginning, in both normoxia ( $\sim 10,000$ cells) and $5 \%$ hypoxia (20,000 cells). On the other hand, cell number at P2 slightly increased 
after differentiation by a factor of approximately $140 \%$ $(\sim 130,000$ cells in normoxia $v s . \sim 180,000$ cells in $5 \%$ hypoxia) compared to the beginning of the assay.

Gene expression analysis of MSC after differentiation showed that cells at $\mathrm{P} 2$ expressed COL2, while cells at P0 not (Fig. 6C). Hypoxia increased COL2 mRNA expression of cells at P2 up to 50-fold ( $p<0.05)$, compared to normoxia. Similar gene expression pattern was observed for ACAN: in hypoxia, expression of ACAN by cells at $\mathrm{P} 0$ was not detectable, while at P2 it was increased almost threefold compared to normoxia (but without reaching statistical significance). In normoxia, ACAN expression at P0 was $40 \%$ lower compared to P2 $(p<0.05)$. COL1 expression was identical in normoxia and hypoxia samples at $\mathrm{P} 2$. In comparison to $\mathrm{P} 2$, cells at $\mathrm{P} 0$ expressed more COL1, especially in normoxia where the expression was almost threefold higher $(p<0.05)$.

\section{Discussion}

In this study, we tested the suitability of injectable microcarriers - derived from medically approved collagen - for three dimensional cultures of human MSC. Successful in vitro differentiation to chondrogenic lineage of MSC cultured on microcarriers proved the potential application of these scaffolds in cell-based treatments for DDD or cartilage repair. Indeed, our previously published results clearly showed that this scaffold material is a key component for MSC undergoing chondrogenic differentiation and we demonstrated that collagen was enhancing the expression of relevant matrix genes such as collagen type I and type II, aggrecan and accumulation of proteoglycans (Bertolo et al., 2012). However, the limitation of these sponge-like scaffolds in practical terms was the absence of a protocol for minimally invasive implantation into the IVD, avoiding further lesions and injuries to the treated disc which might lead to unwanted progression of the degenerative process. The injectability property of microcarriers provides the advantage of easy handling and delivery in tissues using a needle. Furthermore, microcarriers are a versatile compromise between solid and gel-like supports for cell growth, combining properties of the two scaffold types. For instance, the fact that microcarriers are suspended in a solution allows a very efficient diffusion of oxygen and nutrients to all cells, as well as efficient removal of metabolic waste products. Besides, the fibrous rigidity of the microcarriers might provide resistance to extrusion and potentially help MSC to support the loaded environment characteristic for the IVD. Under compression loading conditions, gel-like supports might be less stable than solid scaffolds, due to the release of water from the material structure and direct stress on the polymeric network (Risbud and Bhat, 2001). In addition, injection of gellike scaffolds in IVD face the problem of the high water pressure inside the IVD which could lead to extrusion of the hydrogel including the cells from the site of injection. The solid structure and the heterogeneous texture of microcarriers (Fig. 1) provide a strong constrain against reflux after injection and could effectively promote the retention of cell-constructs into the IVD, while the high pressure expels only the injection solution without cells.

The cells used in this project were human MSC derived from bone marrow extracts. Although the potential of MSC to undergo chondrogenic differentiation is known since long time (Caplan, 1991), to date differentiation to IVDlike cells has not been fully achieved (Gruber et al., 2010). IVD cells share many similarities with chondrocytes, but there are main differences distinguishing the two cell types (Richardson et al., 2008). With the intention of improving chondrogenic differentiation of MSC towards IVD-like phenotype, we introduced in our culture method hypoxia. It has been shown that MSC cultured in hypoxia preserve their native characteristics including clonogenic ability, immunophenotypic profile and multilineage differentiation potential (Dos Santos et al., 2010). Hypoxia provides several advantages for MSC cultures: earlier onset of the exponential growing phase (Dos Santos et al., 2010), reduction of cell oxidative stress (Boregowda et al., 2012) and markedly enhanced chondrogenic differentiation (Feng et al., 2011; Stoyanov et al., 2011). Similarly to those results in $2 \%$ and $5 \%$ hypoxia cultures, MSC seeded on microcarriers expressed aggrecan and collagen type II, whereas in normoxia and $10 \%$ hypoxia collagen type II expression was almost absent. Although at $2 \%$ and $5 \%$ hypoxia had a positive impact on chondrogenesis, at $10 \%$ hypoxia we could not observe any improvement. On the other hand, all three oxygenation levels had beneficial effects on cell proliferation, increasing the yield of cells by approximately $150 \%$.

We showed that we could further improve MSC proliferation by the application of dynamic culture conditions and double the amount of cells after one week compared with the static layout. This beneficial effect originated from the gentle uniform motions of culture vessels inducing flows within the liquid medium phase and transducing shear stresses to cells. Additionally, rotation provided a more evenly distribution of nutrients and $\mathrm{pH}$ levels by avoiding glucose starvation, as well as accumulation of local lactate concentrations. On the other hand, dynamic cultures had an unfavourable effect under chondrogenic differentiation condition of MSC, leading to reduced cell proliferation and expression of collagen type II in comparison with the static culture. We speculate that slow agitation reduced the ability of microcarriers to aggregate, therefore limiting the fundamental step of condensation exerted by MSC during the initial stages of chondrogenesis.

Not only the experimental setup but various factors may have potential influence on the quality and potential of MSC. Long-term passage and in vitro senescence for instance have been reported to reduce osteogenic, adipogenic and chondrogenic differentiation potential of human bone marrow derived MSC (Bertolo et al., 2013). From a prospective of personalised cell-based musculoskeletal regenerative therapies, in vitro culture times should be reduced to a minimum focusing on the use of early cell passages. Thus, we also compared the chondrogenic potential of cells isolated from the same donor, but at a different in vitro age. The comparison was carried out between the mononuclear cell fraction (MNC) from freshly harvested bone marrow (P0), and MSC 
selectively isolated by plastic adherence and expanded in culture (P2) from the same donor. MNCs attached to microcarriers, even if in comparison to plastic flasks the yield of cells after two weeks expansion was lower. In $5 \%$ hypoxia both cells at $\mathrm{P} 0$ and $\mathrm{P} 2$ increased their proliferation rate compared with normoxia. Surprisingly, significant differences were found in the cell number between P0 and $\mathrm{P} 2$ at the beginning of differentiation assay where MSC at P2 were double the number compared to P0. This difference might be explained by (i) uneven amount of cells at the beginning of the assay $(2,000,000 \mathrm{MNCs}$ vs. 40,000 MSC) and (ii) co-existence of a small fraction of MSC within the MNCs population which could have hindered attachment of MSC to microcarriers but led to increased competition for essential nutrients. Interestingly, the differentiation pattern of cells at $\mathrm{P} 0$ and $\mathrm{P} 2$ was also different: P0 MSC expressed higher levels of collagen type I compared to cells at P2, whereas aggrecan and collagen type II expression was much higher at P2 (collagen type II gene expression was almost undetectable in MSC at P0). These results suggest increased chondrogenic potential of early passage MSC compared to freshly isolated MSC. We speculate that the difference in potential might be due to the lower number of stem cells at the beginning of the assay or to gradual in vitro adaptation of the primary MSC culture. Differentiation of MSC resulted, with time, in complete aggregation of microcarriers leading to the formation of one single construct, hampering injectability. Thus, the application of microcarriers for practical approaches assumes the use of MSC in an undifferentiated state or shortly after triggering the differentiation cascade.

In conclusion, improvements in MSC proliferation rate on microcarriers were obtained by culturing cells in $5 \%$ hypoxia and under dynamic regime, while chondrogenic differentiation required a static experimental setup. Injectability of the microcarriers provide minimal invasiveness in potential cell-based applications for the treatment of DDD. With these data we demonstrated the development of fibrous collagen-made microcarriers which are readily available and suitable support for chondrogenic differentiation of MSC in vitro with potential future application as a minimally invasive cell therapy in vivo.

\section{Acknowledgments}

This work was supported by the Swiss Paraplegic Foundation and Swiss National Foundation Grant CR3I3 140717/1.

Author contribution: A. Bertolo: Conception and design, collection and assembly of data, data analysis and interpretation, manuscript writing, final approval of manuscript; S. Häfner: collection and assembly of data, data analysis and interpretation, manuscript writing, final approval of manuscript; A.R. Taddei: collection and assembly of data, data analysis and interpretation, final approval of manuscript; M. Baur: Provision of study material, final approval of manuscript; T. Pötzel: Provision of study material, final approval of manuscript; F. Steffen: Conception and design, final approval of manuscript; $\mathrm{J}$. Stoyanov: Conception and design, collection and assembly of data, data analysis and interpretation, manuscript writing, final approval of manuscript, administrative support.

\section{References}

Allon AA, Butcher K, Schneider RA, Lotz JC (2012) Structured bilaminar coculture outperforms stem cells and disc cells in a simulated degenerate disc environment. Spine (Phila Pa 1976) 37: 813-818.

Battie MC, Videman T, Parent E (2004) Lumbar disc degeneration: epidemiology and genetic influences. Spine (Phila Pa 1976) 29: 2679-2690.

Bertolo A, Mehr M, Aebli N, Baur M, Ferguson SJ, Stoyanov JV (2012) Influence of different commercial scaffolds on the in vitro differentiation of human mesenchymal stem cells to nucleus pulposus-like cells. Eur Spine J 21 Suppl 6: S826-838.

Bertolo A, Mehr M, Janner-Jametti T, Graumann U, Aebli N, Baur M, Ferguson SJ, Stoyanov JV (2013) An in vitro expansion score for tissue-engineering applications with human bone marrow-derived mesenchymal stem cells. J Tissue Eng Regen Med Apr 10: doi: 10.1002/term.1734.

Boregowda SV, Krishnappa V, Chambers JW, Lograsso PV, Lai WT, Ortiz LA, Phinney DG (2012) Atmospheric oxygen inhibits growth and differentiation of marrowderived mouse mesenchymal stem cells via a p53dependent mechanism: implications for long-term culture expansion. Stem Cells 30: 975-987.

Caplan AI (1991) Mesenchymal stem cells. J Orthop Res 9: 641-650.

Chung HJ, Kim IK, Kim TG, Park TG (2008) Highly open porous biodegradable microcarriers: in vitro cultivation of chondrocytes for injectable delivery. Tissue Eng Part A 14: 607-615.

Dos Santos F, Andrade PZ, Boura JS, Abecasis MM, da Silva CL, Cabral JM (2010) Ex vivo expansion of human mesenchymal stem cells: a more effective cell proliferation kinetics and metabolism under hypoxia. J Cell Physiol 223: 27-35.

Ejeskar A, Holm S (1979) Oxygen tension measurements in the intervertebral disc. A methodological and experimental study. Ups J Med Sci 84: 83-93.

Felka T, Schafer R, Schewe B, Benz K, Aicher WK (2009) Hypoxia reduces the inhibitory effect of IL-1beta on chondrogenic differentiation of FCS-free expanded MSC. Osteoarthritis Cartilage 17: 1368-1376.

Feng G, Jin X, Hu J, Ma H, Gupte MJ, Liu H, Ma PX (2011) Effects of hypoxias and scaffold architecture on rabbit mesenchymal stem cell differentiation towards a nucleus pulposus-like phenotype. Biomaterials 32: 81828189.

Freemont AJ, Watkins A, Le Maitre C, Jeziorska M, Hoyland JA (2002) Current understanding of cellular and molecular events in intervertebral disc degeneration: implications for therapy. J Pathol 196: 374-379.

Gorodetsky R, Levdansky L, Gaberman E, Gurevitch O, Lubzens E, McBride WH (2011) Fibrin microbeads loaded with mesenchymal cells support their long-term survival while sealed at room temperature. Tissue Eng Part C Methods 17: 745-755. 
Gruber HE, Deepe R, Hoelscher GL, Ingram JA, Norton HJ, Scannell B, Loeffler BJ, Zinchenko N, Hanley EN, Tapp H (2010) Human adipose-derived mesenchymal stem cells: direction to a phenotype sharing similarities with the disc, gene expression profiling, and coculture with human annulus cells. Tissue Eng Part A 16: 2843-2860.

Huang CY, Reuben PM, D'Ippolito G, Schiller PC, Cheung HS (2004) Chondrogenesis of human bone marrow-derived mesenchymal stem cells in agarose culture. Anat Rec A Discov Mol Cell Evol Biol 278: 428436.

Ishihara H, Urban JP (1999) Effects of low oxygen concentrations and metabolic inhibitors on proteoglycan and protein synthesis rates in the intervertebral disc. J Orthop Res 17: 829-835.

Ivanovic Z (2009) Hypoxia or in situ normoxia: The stem cell paradigm. J Cell Physiol 219: 271-275.

Malda J, Frondoza CG (2006) Microcarriers in the engineering of cartilage and bone. Trends Biotechnol 24: 299-304.

Malonzo C, Chan SC, Kabiri A, Eglin D, Grad S, Bonel HM, Benneker LM, Gantenbein-Ritter B (2013) A papain-induced disc degeneration model for the assessment of thermo-reversible hydrogel-cells therapeutic approach. J Tissue Eng Regen Med Jan 9: doi: 10.1002/term.1667.

Martin Y, Eldardiri M, Lawrence-Watt DJ, Sharpe JR (2011) Microcarriers and their potential in tissue regeneration. Tissue Eng Part B Rev 17: 71-80.

Masuda K, Oegema TR, Jr., An HS (2004) Growth factors and treatment of intervertebral disc degeneration. Spine (Phila Pa 1976) 29: 2757-2769.

Meisel HJ, Siodla V, Ganey T, Minkus Y, Hutton WC, Alasevic OJ (2007) Clinical experience in cell-based therapeutics: disc chondrocyte transplantation A treatment for degenerated or damaged intervertebral disc. Biomol Eng 24: 5-21.

Osborne A, Blake C, Fullen BM, Meredith D, Phelan J, McNamara J, Cunningham C (2012) Prevalence of musculoskeletal disorders among farmers: A systematic review. Am J Ind Med 55: 143-158.

Pittenger MF, Mackay AM, Beck SC, Jaiswal RK, Douglas R, Mosca JD, Moorman MA, Simonetti DW, Craig S, Marshak DR (1999) Multilineage potential of adult human mesenchymal stem cells. Science 284: 143-147.

Purmessur D, Schek RM, Abbott RD, Ballif BA, Godburn KE, Iatridis JC (2011) Notochordal conditioned media from tissue increases proteoglycan accumulation and promotes a healthy nucleus pulposus phenotype in human mesenchymal stem cells. Arthritis Res Ther 13: R81.

Richardson SM, Hughes N, Hunt JA, Freemont AJ, Hoyland JA (2008) Human mesenchymal stem cell differentiation to NP-like cells in chitosan-glycerophosphate hydrogels. Biomaterials 29: 85-93.

Risbud MV, Bhat SV (2001) Properties of polyvinyl pyrrolidone/beta-chitosan hydrogel membranes and their biocompatibility evaluation by haemorheological method. J Mater Sci Mater Med 2: 75-79.

Sakai D, Mochida J, Iwashina T, Hiyama A, Omi H, Imai M, Nakai T, Ando K, Hotta T (2006) Regenerative effects of transplanting mesenchymal stem cells embedded in atelocollagen to the degenerated intervertebral disc. Biomaterials 27: 335-345.

Sart S, Errachid A, Schneider YJ, Agathos SN (2013) Modulation of mesenchymal stem cell actin organization on conventional microcarriers for proliferation and differentiation in stirred bioreactors. J Tissue Eng Regen Med 7: 537-551.

Schrobback K, Klein TJ, Crawford R, Upton Z, Malda J, Leavesley DI (2012) Effects of oxygen and culture system on in vitro propagation and redifferentiation of osteoarthritic human articular chondrocytes. Cell Tissue Res 347: 649-663.

Scotti C, Osmokrovic A, Wolf F, Miot S, Peretti GM, Barbero A, Martin I (2012) Response of human engineered cartilage based on articular or nasal chondrocytes to interleukin-1beta and low oxygen. Tissue Eng Part A 18: 362-372.

Stoyanov JV, Gantenbein-Ritter B, Bertolo A, Aebli N, Baur M, Alini M, Grad S (2011) Role of hypoxia and growth and differentiation factor-5 on differentiation of human mesenchymal stem cells towards intervertebral nucleus pulposus-like cells. Eur Cell Mater 21: 533-547.

Woods BI, Vo N, Sowa G, Kang JD (2011) Gene therapy for intervertebral disk degeneration. Orthop Clin North Am 42: 563-574.

Yang X, Wang D, Hao J, Gong M, Arlet V, Balian G, Shen FH, Li XJ (2011) Enhancement of matrix production and cell proliferation in human annulus cells under bioreactor culture. Tissue Eng Part A 17: 1595-1603.

\section{Discussion with Reviewers}

Reviewer I: For which patient population do you envision your treatment? It has been shown by others that needle puncture of the IVD does induce disc degeneration in vivo and in vitro (Masuda et al., 2005; Michalek, 2010).

Authors: We envision the use of microcarriers/cells for patient suffering of not severe intervertebral disc degeneration (DDD). Key point in the treatment of the DDD is to intervene in the early stages of the disease, when end plates are not yet calcified and still metabolically active. This is in order to inject cells into an environment which can sustain their activity. Kang in 2010 (in the commentary: "Does a needle puncture into the annulus fibrosus cause disc degeneration?") answered the issue raised by Michalek in these terms: Whatever the case may be, it would seem obvious that if future therapies are devised for disc degeneration, there is no way to escape "injecting" the disc with such agents for local delivery. With the results of the study by Michalek et al., it makes empirical sense to use the least disruptive injection methods possible and introduce therapeutic agents that can help quickly heal the defect as rapidly as possible. Microcarriers are injectable thorough a thin (sub-mm) needle, causing minor damage to the annulus fibrosis, and our expectation is that they will take part in the repair of the injection defect as well. 
Reviewer II: How can one make sure that in a human clinical case the micro-carriers will not come out after $>2 \mathrm{M}$ cycles of cyclic compressive loading? What about complex loading movements? Will the cells survive? Will the micro-carriers stay in place without sealing the needle track? A biomechanical evaluation would be needed as a next step.
Authors: We are currently writing a new paper where microcarriers were injected in cadaveric spine units isolated from dogs and then disc were subjected to cyclic compressive loading inducing compression with bending in 4 directions, where we will answer all these questions. 